\title{
RAPID COMMUNICATION
}

\section{Attention and memory of medical residents after a night on call: a cross-sectional study}

\author{
Aida Cristina Suozzo,' Stella Maria Malta," Gislaine Gil,"' Fabiana Tintori,' ${ }^{\text {IV }}$ Shirley Silva Lacerda, \\ Luiz Antonio Nogueira-Martins ${ }^{\mathrm{VI}}$ \\ 'Emergency Room of Hospital Central of Irmandade da Santa Casa de Misericórdia de São Paulo (ISCMSP), Department of Psychiatry and Medical \\ Psychology, School of Medical Science of Santa Casa de Misericórdia de São Paulo (FCMSCSP). "Neuropsychologist; Interdisciplinary Clinical Neurosciences \\ Laboratory, Department of Psychiatry, Universidade Federal de São Paulo (Unifesp). 'II Neuropsychologist; Institute of Psychiatry of Hospital das Clínicas da \\ Faculdade de Medicina da Universidade de São Paulo (HCFMUSP). IV Psychologist, ISCMSP, São Paulo. V Neuropsychologist; Universidade Federal de São \\ Paulo (Unifesp). ${ }^{\text {VI } A s s o c i a t e ~ P r o f e s s o r, ~ D e p a r t m e n t ~ o f ~ P s y c h i a t r y, ~ U n i v e r s i d a d e ~ F e d e r a l ~ d e ~ S a ̃ o ~ P a u l o ~(U n i f e s p) . ~}$
}

Email: aidacristinasuozzo@terra.com.br

Tel.: 551121767000

\section{INTRODUCTION}

Medical residency is generally acknowledged to be stressful, especially during the internship period. Residents are susceptible to fatigue and chronic sleep deprivation due to their prolonged work hours and rotating work schedules. ${ }^{1}$

For the first time, in 2003, the Accreditation Council for Graduate Medical Education (ACGME) in the U.S. implemented limits of 30 consecutive work hours and 80 weekly hours for resident physicians across all specialties, to protect doctors and patients from the unsafe conditions that can result from excessive fatigue. ${ }^{2}$ Following the implementation of these regulations, increasing public and academic attention has been focused on the role of resident physicians' fatigue and the occurrence of medical errors, percutaneous needle sticks, laceration injuries and post-call motor vehicle crashes. ${ }^{3,4} \mathrm{~A}$ landmark study of resident physicians working in an adult intensive care unit has received a great deal of attention in the medical community. ${ }^{5}$ This study found that residents made more medical errors when they worked frequent shifts of at least $24 \mathrm{~h}$ than when they worked shorter shifts.

A work hour limit of $60 \mathrm{~h}$ per week was instituted in Brazil in $1981,{ }^{6}$ but even with this regulation, many studies have identified problems during medical residency, such as depression and anxiety, ${ }^{7}$ burnout, ${ }^{8}$ daytime sleepiness ${ }^{9}$ and impairment of quality of life. ${ }^{10,11}$ The aim of our study was to compare the cognitive performance of first-year internal medicine residents after a night on call in the emergency room (ER) and after a night off duty during training using neuropsychological tests. The study was performed during the normal shift on an internal medicine ward at a university hospital with a work hour restriction of $60 \mathrm{~h}$ per week.

\section{METHODS AND MATERIALS}

a.) Participants

This cross-sectional study was conducted between February 2005 and January 2006 in the emergency room

Copyright (c) 2011 CLINICS - This is an Open Access article distributed under the terms of the Creative Commons Attribution Non-Commercial License (http:// creativecommons.org/licenses/by-nc/3.0/) which permits unrestricted noncommercial use, distribution, and reproduction in any medium, provided the original work is properly cited.
(ER) of a tertiary hospital. After the approval, we invited all residents $(n=40)$ in Department of Internal Medicine at Irmandade da Santa Casa de Misericórdia de São Paulo (ISCMSP; a charity and education hospital) in São Paulo, Brazil to participate. Thirty-eight of the 40 first-year internal medicine residents agreed to participate and provided written informed consent.

The exclusion criteria were as follows: refusal to participate in any phase of the study; a current substancerelated disorder, including alcohol or drug abuse; current use of medications known to affect the sleep/wake cycle or daytime alertness; neurological disease; attention deficit/ hyperactivity disorder; a lifetime history of traumatic brain injury/vascular brain disorder; severe, uncompensated sensory loss (deafness, muteness, or blindness); and participation in another medical residency program in the previous year. We included both residents working a normal shift on an internal medicine ward and residents who had not been on call overnight for at least $72 \mathrm{~h}$.

\section{b.) Cognitive evaluation}

A battery of neuropsychological ${ }^{12}$ tests was performed according to the instructions in the user handbooks. The tests were conducted by trained neuropsychology G.G. (Gislaine Gil) and psychology students and took nearly 45 min. The sequence of neuropsychological tests and the cognitive functions assessed are presented in Table 1.

\section{c.) Procedure}

The first year of training consists of three months spent working in medical wards. The residents' daily clinical routine consists of working from 7:30 a.m. until 5 p.m., Monday through Friday. Residents focus on patient care in the inpatient wards and ambulatory medicine in the outpatient clinics. In addition, they attend seminars and spend every seventh night on call, on average (i.e., residents usually have one overnight on-call period per week in the ER).

The assessments were performed for each resident twice (only from Monday through Friday): (1) the first evaluation (stage 1) was conducted after a night on call in the ER (7:30 p.m. to 7:30 a.m. the next morning), and (2) the second evaluation (stage 2) was conducted after a night spent off duty (7:30 p.m. to 7:30 a.m. the next morning). Each resident 
Table 1 - Neuropsychological tests and functions.

\begin{tabular}{|c|c|}
\hline Neuropsychological tests & Cognitive Functions \\
\hline Digit Span (WAIS III) & $\begin{array}{l}\text { Assesses attention and immediate } \\
\text { memory by presenting sequences of } \\
\text { numbers with a gradual increase in } \\
\text { difficulty, both forward and } \\
\text { reverse. }\end{array}$ \\
\hline Span Spatial (WMS III) & $\begin{array}{l}\text { Assesses attention and immediate } \\
\text { memory using a motor task } \\
\text { involving visuospatial location } \\
\text { sequences with progressively } \\
\text { increasing difficulty. }\end{array}$ \\
\hline Trail Making Test $A$ and $B$ & $\begin{array}{l}\text { Assesses attention, visual tracking, } \\
\text { mental flexibility, information } \\
\text { processing speed and motor } \\
\text { function. }\end{array}$ \\
\hline $\begin{array}{l}\text { Rey Auditory Verbal Learning } \\
\quad(R A V L T)\end{array}$ & $\begin{array}{l}\text { Assesses verbal learning and memory } \\
\text { using a list of words that are } \\
\text { repeated after five attempts. After } \\
20 \text { min, the retention test is } \\
\text { conducted, followed by the } \\
\text { recognition test. }\end{array}$ \\
\hline
\end{tabular}

Reference Source: Neuropsychological assessment, Lezak M., 3 Ed, New York, Oxford University Press, 1995.

was assigned a numerical identifier, and the evaluation order was determined by random drawing. There were at least eight weeks between the first and second evaluations.

\section{d.) Statistical analysis}

We used the SPSS software package version 14.0 (SPSS Inc., Chicago, IL) for all statistical evaluations. The frequencies and means \pm the standard deviation (SD) of all data were examined. The normality of the data was determined using the Kolmogorov-Smirnov test. Comparisons between stages were performed using a paired $\mathrm{t}$ test and Wilcoxon tests for normally and non-normally distributed data, respectively. The effect sizes were calculated using Cohen's d coefficient to determinate the differences between the first and second evaluations.
Differences were considered statistically significant when $P<0.05$.

\section{RESULTS}

Of the 38 internal medicine residents, 21 (55.3\%) were male, $35(92.11 \%)$ were unmarried, and one $(2.6 \%)$ was a smoker. The mean age was 25.4 years $(S D=1.4)$. At stage 1 , two residents did not perform the following evaluations: digit span backward (subject no. 1), digit span forward (subject no. 1) and RAVLT - recognition list A (subject no. 1 and subject no. 2).

After a night on call, the performance of the residents was worse on the Trail Making Test A ( $p=0.016)$, which assesses attention and the RAVLT-Trial 1 (which assesses immediate recall) $(p=0.028)$, the RAVLT-Trial 7 (which assesses delayed recall $)(p=0.016)$, the RAVLT-List $B(p=0.006)$, the RAVLT-Speed of forgetting ( $p=0.007)$, and the RAVLTtotal (trials 1 to 5$)(p=0.035)$, which assess task verbal memory and learning, compared to their scores after a night off duty (Table 2).

\section{DISCUSSION}

To our knowledge, this is the first Brazilian study to evaluate the cognitive performance of medical residents. This study is unique in that it was conducted with young residents and used extensive neuropsychological assessments. Furthermore, these findings are relevant to everyday clinical practice and therefore should be of considerable interest to people involved in clinical practice.

We found no differences in the verbal attention span (digit span forward), the visuomotor memory (spatial span forward) and the working memory (digit/spatial backward) of residents, which is in accordance with Deary et al. ${ }^{13}$ Moreover, the lengths of our tests further validate these results; according to Veasy et al. ${ }^{14}$, a shorter task duration decreases the likelihood of detecting performance deficits.

However, among tasks that involve time, the performance of the residents on Trail A was worse with respect to selective attention and processing speed $(\mathrm{p}=0.016)$, similar

Table 2 - Cognitive performance of internal medicine residents after Stage 1 and Stage $2(n=38)$.

\begin{tabular}{|c|c|c|c|c|}
\hline \multirow[b]{2}{*}{ Neuropsychological tests } & \multicolumn{2}{|r|}{ Stage 2} & \multirow[b]{2}{*}{ p-values } & \multirow[b]{2}{*}{ Cohen's d } \\
\hline & Mean $( \pm S D)$ & Mean $( \pm S D)$ & & \\
\hline Digit Span Forward* & $10.03(1.70)$ & $10(1.693)$ & $0.947^{a}$ & 0.01 \\
\hline Digit Span Backward* & $7.86(2.188)$ & $8.29(2.217)$ & $0.213^{a}$ & -0.20 \\
\hline Spatial Span Forward & $8.92(1.937)$ & $8.87(2.133)$ & $0.897^{a}$ & 0.02 \\
\hline Spatial Span Backward & $7.34(2.184)$ & $7.50(1.997)$ & $0.687^{a}$ & -0.07 \\
\hline TMT - A (seconds) & $37.66(11.883)$ & $33.84(13.102)$ & $0.016^{b}$ & 0.30 \\
\hline$T M T$ - B (seconds) & $73.58(32.232)$ & $67.66(28.005)$ & $0.068^{\mathrm{b}}$ & 0.19 \\
\hline RAVLT - Trial 1 & $8.05(2.681)$ & $9.50(3.029)$ & $0.028^{a}$ & -0.50 \\
\hline RAVLT - Total & $59.24(8.152)$ & $62.71(10.139)$ & $0.035^{\mathrm{a}}$ & -0.37 \\
\hline RAVLT - List B & $6.97(2.007)$ & $8.03(2.260)$ & $0.006^{a}$ & -0.49 \\
\hline RAVLT - Trial 6 & $12.95(1.958)$ & $13.13(2.429)$ & $0.665^{\mathrm{a}}$ & -0.08 \\
\hline RAVLT - Trial 7 & $12.42(2.657)$ & $13.53(2.424)$ & $0.016^{b}$ & -0.43 \\
\hline RAVLT - Recognition (List A) & $14.31(2.573)$ & $14.82(0.609)$ & $0.071^{\mathrm{b}}$ & -0.34 \\
\hline RAVLT - Intrusions & $0.55(1.370)$ & $0.08(0.487)$ & $0.064^{\mathrm{b}}$ & 0.45 \\
\hline RAVLT - Proactive interference & $0.94(0.41)$ & $0.90(0.30)$ & $0.912^{\mathrm{b}}$ & 0.05 \\
\hline RAVLT - Retroactive interference & $0.91(0.10)$ & $0.92(0.11)$ & $0.621^{\mathrm{b}}$ & -0.09 \\
\hline RAVLT - Speed of forgetting & $0.95(0.17)$ & $1.03(0.10)$ & $0.007^{\mathrm{b}}$ & -0.57 \\
\hline
\end{tabular}

*One resident was excluded in the analyses of this test $(n=37) ; * *$ Two residents were excluded in the analyses of this test ( $n=36)$; $a$ : paired $t$-test; b: Wilcoxon test; SD: Standard deviation; TMT: Trail Making Test; RAVLT: Rey Auditory Verbal Learning Test. 


\section{RAVLT: after nights on call and off duty}

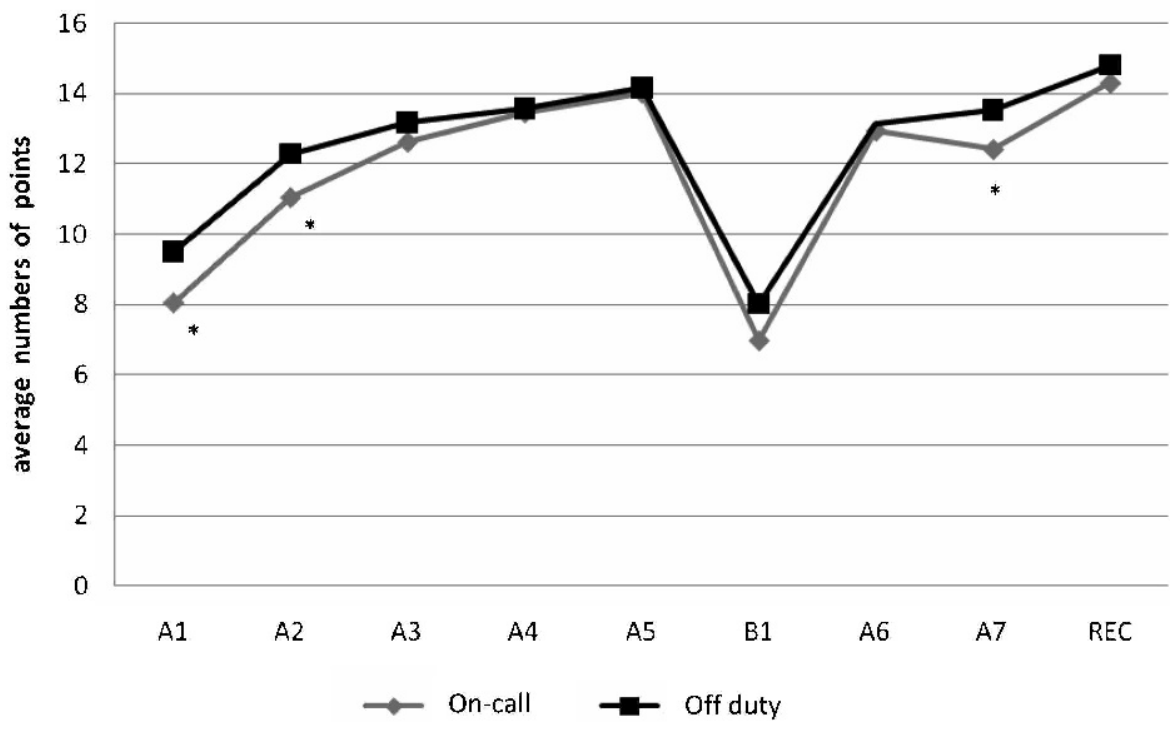

Figure 1 - Verbal learning curve (number of words recalled in each attempt) for the RAVLT.

$A 1, A 2, A 3, A 4, A 5, A 6$, and $A 7$ : number of words remembered from list $A ; B 1$ : number of words remembered from list $B ;$ REC: number of words from list $A$ that were recognized. ${ }^{*} p<0.05$

to the results of Dominguez et al.'s ${ }^{15}$ study involving pediatrics residents. Nevertheless, for Trail B (the second part of the test), we were surprised to find negative results similar to those of Lehmann et al. ${ }^{16}$ The results indicate that when this test was applied, residents were able to maintain a high level of concentration for a predictable amount of time.

After a night on call, the performance of residents was worse with respect to verbal immediate memory (Trial 1) and delayed recall (Trial 7), as assessed by the RAVLT. Moreover, we detected a significant distractor effect; i.e., the second list of words presented (list B) acted as a distractor. Furthermore, we observed that the speed of forgetting after a night on call was significantly greater than after a night off duty.

Also in the RAVLT, verbal learning was significantly worse after a night on call (the score total of the RAVLT test). These results are demonstrated by the verbal learning curve (Figure 1), in which residents tested after a night on call required three attempts to achieve a level of performance similar to that achieved with a single attempt after of night off duty (Trials 1, 2 and 3). After these initial attempts, the performances were similar for both stages for the remaining attempts (Trials 4 and 5).

Studies analyzing relationships between residents' performance and long work hours have used a variety of psychometric tests. However, differences in study design, medical specialties tested and methods for cognitive testing have limited the ability to compare studies. Moreover, these studies are susceptible to criticism because they have not demonstrated that working long hours influence clinical performance. $^{14}$

In spite of these criticisms, we recognize that it is difficult to design a study to evaluate the clinical implications of cognitive deficits. Therefore, we designed a study that combined several features. Importantly, we sampled a homogeneous group of doctors. The subjects were relatively young, without previous work experience, and served as their own controls (Stage 2). All of the first evaluations were performed after a night on call to diminish the opportunity to learn (because the residents were tired). In addition, residents were all subjected to the same workload in the internal medicine ward with the same number of working hours per week, including night shifts. The residents were all exposed to the same environmental burden in the ER, which is a highly stressful emergency department with few opportunities for rest. Thus, our study could be considered a realistic model of a day during the first year of an internal medicine residency at a Brazilian teaching hospital.

Educators involved in training residents should take note of these results. Extended work shifts can adversely affect learning. ${ }^{2-4}$ Adequate sleep is crucial for maintaining attention and also plays an important role in memory consolidation and learning ${ }^{2}$ at one of the most important stages of a physician's medical career.

\section{CONCLUSIONS}

This study revealed that first-year Brazilian internal medicine residents have worse cognitive functioning after a night on call than after a night off, as assessed by neuropsychological tests. Accordingly, residency programs should consider these results when planning their educational programs.

\section{Limitations}

The results of this study should be taken in context, given that they came from a single institution and relate to firstyear medical residents within a single medical specialty.

\section{ACKNOWLEDGMENTS}

The authors thank all of the internal medicine residents for their participation in this study and Ricardo Asensio Rodriguez and Eliane Villar for administering the neuropsychological tests. 


\section{REFERENCES}

1. Rosen IM, Gimotty PA, Shea JA, Bellini LM. Evolution of sleep quantity, sleep deprivation, mood disturbances, empathy, and Burnout among interns. Acad Med. 2006; 81:82-5, doi: 10.1097/00001888-200601000-00020.

2. National Academy of Sciences. Residency duty hours: enhancing sleep, supervision and safety. 2009. [on line] [Cited 2010 Nov 10 ] Available from: URL: http:/ /www.nap.edu/catalog/12508.html

3. Szklo-Coxe M. Are residents' extended shifts associated with adverse events? Plos Med. [serial on line] 2006, 3(12): e497. [Cited 2010 Nov 10] Available from: URL: http://www.plosmedicine.org, doi: 10.1371/ journal.pmed.0030497

4. Barger LK, Ayas NT, Cade BE, Cronin JW, Rosner B, Speizer FE, et al. Impact of extended duration shifts on medical errors, adverse events and attentional failures. Plos Med. 2006; 3(12): e487. [Cited 2010 Nov 10] Available from: URL: http://www.plosmedicine.org, doi: 10.1371/ journal.pmed.0030487

5. Landrigan CP, Rothschild JM, Cronin JW, Kaushal R, Burdick E, Katz JT, et al. Effect of reducing interns' work hours on serious medical errors in intensive care units. N Engl J Med. 2004; 351:1838-48, doi: 10.1056/ NEJMoa041406.

6. Brasil. Presidência da República. Casa Civil. Lei 6.932 de 07/06/1981. Dispõe sobre as atividades do médico residentes e dá outras providências. [on line] Diário Oficial da União, Brasília, DF, 09/07/1981. [Citado 2010 Nov 10] Disponível em: URL: http://www.planalto.gov.br/ ccivil 03/Leis/L6932.htm

7. Peterlini M, Tiberio IF, Saadeh A, Pereira JC, Martins MA. Anxiety and depression in the first year of medical residency training. Med Educ. 2002; 36:66-72, doi: 10.1046/j.1365-2923.2002.01104.x

8. Lima FD, Buunk AP, Araujo MBJ, Chaves JGM, Muniz DLO, Queiroz LB. Burnout syndrome in residents of the Federal University of Uberlândia -
2004. Rev Bras Educ Med. 2007; 31:137-46, doi: 10.1590/S010055022007000200004.

9. Asaiag PE, Perotta B, Martins MA, Tempski P. Assessment of quality of life, daytime sleepiness and Burnout in medical residents. Rev Bras Educ Med. 2010; 34.422-9, doi: 10.1590/S0100-55022010000300012.

10. Oliveira Filho GE, Sturn EJ, Sartorato AE. Compliances with common program requirements in Brazil: its effects on resident's perceptions about quality of life and the educational environment. Acad Med. 2005; 80:90-102, doi: 10.1097/00001888-200501000-00022.

11. Macedo PCM, Cítero VA, Schenkman S, Nogueira-Martins MCF, Morais MB, Nogueira-Martins LA. Health related quality of life predictors during medical residency in a random, stratified sample of residents. Rev Bras Psiquiatr. 2009; 31:119-24, doi: 10.1590/S1516-4446200 9000200007.

12. Spreen O, Strauss EA. Compendium of neuropsychological tests: administration, norms and commentary. New York: Oxford University Press; 1998.

13. Deary IJ, Tait R. Effects of sleep disruption on cognitive performance and mood in medical house officers. Br Med J (Clin Res J). 1987, 295:1513-6, doi: 10.1136/bmj.295.6612.1513.

14. Veasey S, Rosen R, Barzansky B, Rosen I, Owens J. Sleep los and fatigue in residency training; a reappraisal. JAMA. 2002; 288:1116-24, doi: 10 . 1001/jama.288.9.1116.

15. Dominguez P, Grosso ML, Pagotto B, Taliercio V, Allegri R. Efectos de La privación de sueño em el desempeño de los médicos residentes de pediatria. Arch Argent Pediatr. 2009; 107:241-5.

16. Lehmann KS, Martus P, Little ElkS, Maass H, Holmer C, Zurbuchen U, et al. Impact of sleep deprivation on medium-term psychomotor and cognitive performance of surgeons: prospective cross-over study with a virtual surgery simulator and psychometric tests. Surgery. 2009; 147:246-54, doi: 10.1016/j.surg.2009.08.007. 